\title{
BAHASA PIJIN MAHASISWA THAILAND DI KOTA TANGERANG PROVINSI BANTEN
}

\author{
Ira Anisa Purawinangun ${ }^{1} \&$ Irpa Anggriani Wiharja ${ }^{2}$ \\ ${ }_{1,2}$ Universitas Muhammadiyah Tangerang \\ Jl. Perintis Kemerdekaan I No.1, Babakan, Kec. Tangerang, Kota Tangerang, Banten \\ Email: irapurawinangun@yahoo.com ${ }^{1}$, irpawiharja@gmail.com ${ }^{2}$
}

\begin{abstract}
Abstrak
Penelitian ini bertujuan untuk mendeskripsikan bahasa Pijin di lingkungan mahasiswa Thailand yang tinggal di daerah Tangerang. Data dalam penelitian ini berupa pembentukan bahasa baru dari beberapa bahasa atau pijinisasi. Penelitian ini memiliki dua jenis data yaitu data primer dan sekunder. Data primer dalam penelitian ini adalah data asli yang didapat dengan wawancara langsung. Sedangkan data sekunder dalam penelitian ini adalah bukubuku referensi yang berkaitan dengan objek penelitian. Jenis penelitian ini adalah penelitian deskriptif kualitatif. Teknik pengumpulan data dalam penelitian ini menggunakan teknik observasi, wawancara, dan dokumentasi. Dalam penelitian ini metode analisis data yang digunakan adalah metode analisis isi. Dari hasil penelitian didapatkan proses pijinisasi secara umum merupakan penyederhanaan bentuk bahasa. Misalnya, secara morfologis (struktur kata) dan sintaksis (struktur gramatikal), toleransi terhadap variasi-variasi fonologis (pengucapan), reduksi sejumlah fungsi, dan peminjaman secara luas kata dari beberapa bahasa.
\end{abstract}

Kata kunci: Bahasa Pijin, Mahasiswa Thailand

\section{PIDGIN LANGUAGE OF THAILAND STUDENTS IN TANGERANG CITY BANTEN PROVINCE}

\begin{abstract}
The aim of this research was to describe the pidgin language of Thailand students who lived in Tanggerang. The data in this research was the forming of new language from some others languages or it is called as pidgin. This research had two types of data; primary and secondary data. Primary data was the result of interview. While, secondary data was all references that relevance to the research. Due to the research problem, the qualitative descriptive research design was used. There were some techniques used to collect the data such as observation, interview, and documentation. In this research, the content analysis data analysis method was also used. So, based on the analysis of data, the result of the research was pidgin as the simplify of language form. For example, morpholgy form, syntax, tolerance of phonology variance, reduction of some function, and absorption of language from other languages.
\end{abstract}

Keywords: Pidgin Language, Thai Students 


\section{A. Pendahuluan}

Bahasa merupakan alat komunikasi yang digunakan manusia untuk berinteraksi. Sebagai alat komunikasi karena bahasa benar-benar unik dan mampu mewakili ungkapan pikiran dan perasaan penuturnya melalui variasi susunan predikat dan unsur sebelum dan sesudahnya yang membentuk kalimat sehingga terjadi interaksi antara penutur dengan mitra tutur (Noermanzah, 2017:13). Bahasa yang berada di dunia ini beraneka ragam, bukan hanya dua atau tiga, tetapi ada lebih dari berjuta-juta ragam bahasa yang ada di dunia ini. Bahasa Indonesia dan bahasa Melayu merupakan salah satu bahasa dari bahasa-bahasa yang ada. Kedua bahasa tersebut memiliki persamaan dan perbedaan di dalamnya. Di Indonesia, bahasa Indonesia merupakan bahasa resmi rakyat Indonesia, sedangkan bahasa Melayu merupakan bahasa daerah yang di pakai di daerah-daerah tertentu. Negara Thailand merupakan tetangga negara Indonesia yang sebagian penduduk bagian selatannya menggunakan bahasa Melayu. Salah satu daerah selatan Thailand yang menggunakan bahasa Melayu adalah Patani.

Pada zaman sekarang, banyak orang-orang dari negara lain yang datang ke Indonesia dengan tujuan masing-masing. Salah satunya adalah para pelajar Thailand yang datang ke Indonesia untuk menempuh ilmu di Indonesia. Universitas Muhammadiyah Tangerang merupakan salah satu lembaga yang menjalani program pertukaran pelajar tersebut. Para mahasiswa Thailand tersebut berasal daerah Patani yang merupakan bagian selatan dari negara Thailand.

Penggunaan bahasa yang digunakan juga mengalami percampuran, karena mereka biasa menggunakan bahasa Thai atau bahasa Melayu Thailand dalam kehidupan sehari-hari dan saat datang ke Indonesia untuk belajar. Mereka juga diharuskan untuk menggunakan bahasa Indonesia, baik di lingkungan tempat tinggal selama di Indonesia, maupun di tempat perkuliahan. Dari sinilah muncul bahasa-bahasa campuran atau bisa disebut bahasa pijin atau pidgin, yaitu percampuran antara bahasa Melayu Thailand dengan bahasa Indonesia.

Bahasa Melájoé atau disebut juga bahasa Djawi adalah cabang rumpun bahasa yang meliputi kabanyakan pulau nusantara. Keserupaannya dalam kosa kata, melainkan juga dalam cara pembentukan kata dan seluruh bangunan 
bahasanya, telah membuktikan bahwa itulah alasannya. Menurut Blumenbach (dalam Simanjuntak, 2010), seorang ahli berkebangsaan Jerman, membuat klasifikasi ras dari bangsa-bangsa di dunia menjadi lima kelompok, yaitu Kakukasia, Mongolia, Ethiopia, Amaerik, dan Melayu-Polinesia. Ras MelayuPolinesia mendiami Pulau Madagaskar (Malagasi), meliputi seluruh Kepulauan Nusantara terus je Semenanjung Malaka, sampai ke Filipina, Taiwan (Formosa), dan pulau-pulau di sekitar lautan Teduh.

Keturunan ras Melayu-Polinesia (Austronesia) inilah yang menjadi penduduk asli Semenanjung Malaka dan di Kepulauan Asia Tenggara. Kelompok Melayu yang datang ke Indoneaua dibagi menjadi dua, kelompok pertama disebut Melayu Tua dan yang terakhir disebut Melayu Muda. Ada berbagai pendapat yang berkenaan dengan nama Melayu: (1) Melayu berasal dari kata "Mala", yang berarti mula dan "Yu", yang berarti negeri, (2) dalam bahasa Tamil, Melayu atau Melayur berarti "Tanah Tinggi", dan (3) Melayu dalam bahasa Jawa berarti "deras" atau "lari".

Secara umum kebudayaan dari suku bangsa Melayu memiliki perbedaan. Perbedaan utamanya dapat dilihat dalam bidang bahasanya, yakni dalam pengucapan bahasa (dialek). Perbedaan dialek tersebut muncul karena adanya percampuran dengan bahasa-bahasa dari suku bangsa lain. Walaupun dialeknya berbeda, makna kata bahasanya tetap sama. Oleh karena itu, artikel ini memuat pembahasan tentang analisis bahasa Pijin Melayu Thailand pada mahasiswa Thailand di lingkungan Tangerang. Bahasa Pijin yang muncul tersebut merupakan perpaduan antara bahasa Melayu Thailand dengan bahasa Indonesia.

Penelitian terkait dengan bahasa Pijin mahasiswa Thailand di Kota Tanggerang Provinsi Banten, pernah dilakukan oleh Mutoharoh, dkk. (2018:95) dengan hasil penelitian yang menunjukkan bahwa terdapat interferensi pada karangan narasi mahasiswa Thailand semester IV Program Studi Pendidikan Bahasa dan Sastra Indonesia, Universitas Muhammadiyah Tangerang. Karangan yang mahasiswa susun, sebagian besar masih menggunakan bahasa Melayu dalam berkomunikasi secara tulisan. Kata yang terinterferensi pada bentuk afiksasi kategori prefiks, sufiks, kombinasi afiks, konfiks, reduplikasi, dan komposisi sedangkan pada afiks kategori infiks tidak terdapat interferensi. Bentuk 
Ira Anisa Purawinangun ${ }^{1} \&$ Irpa Anggriani Wiharja ${ }^{2}$

yang sering terinterferensi yaitu afikasisi kategori prefiks, konfiks, dan komposisi. Hasil penelitian ini lingkupnya hanya sebatas pada kemampuan menulis mahasiswa pada semester IV Program Studi Pendidikan Bahasa dan Sastra Indonesia, Universitas Muhammadiyah Tangerang. Sedangkan penelitian pada pembahasan ini lebih kepada bahasa Pijin di Lingkungan Mahasiswa Thailand yang tinggal di daerah Tangerang.

\section{B. Metode Penelitian}

Pendekatan yang dilakukan dalam penelitian ini adalah metode deskriptif kualitatif. Menurut Sudaryono (2018) penelitian deskriptif kualitatif merupakan penelitian yang berupaya menganalisis kehidupan sosial dengan menggambarkan dunia sosial dari sudut pandang atau interpretasi individu (informan) dalam latar alamiah. Menurut Syamsudin \& Vismania (2009) penelitian kualitatif adalah suatu pendekatan yang juga disebut pendekatan karena biasanya peneliti mengumpulkan data dengan cara bertatap muka langsung dan berinteraksi dengan orang-orang di tempat penelitian.

Moleong (2010) mengatakan bahwa penelitian kualitatif adalah penelitian yang bermaksud untuk memahami fenomena tentang apa yang dialami oleh subyek penelitian misalnya, perilaku, persepsi, motivasi, tindakan, secara holistik dengan cara deskripsi dalam bentuk kata-kata dan bahasa, pada suatu konteks khusus yang alamiah dan dengan memanfaatkan berbagai metode. Jadi, pendekatan kualitatif merupakan pendekatan yang dilakukan peneliti untuk mengumpulkan data atau mendeskripsikan dalam bentuk kata-kata dan bahasa yang dilakukan dengan cara bertatap muka atau berinteraksi langsung.

Data dalam penelitian ini adalah bahasa Pijin yang digunakan oleh Mahasiswa Thailand yang tinggal di daerah Tangerang khususnya mahasiswa yang kuliah di Universitas Muhammadiyah Tangerang. Teknik analisis data dengan langkah reduksi data (data reduction), penyajian data (data display), dan penarikan kesimpulan dan verifikasi. Uji keabsahan data dengan menggunakan ketekunan dan triangulasi data dari kegiatan wawancara, observasi, dan dokumentasi. 


\section{Hasil Penelitian dan Pembahasan}

\section{Hasil Penelitian}

Ada beberapa hasil penelitian disajikan pada sub bagian ini, yaitu: bentuk bahasa Melayu Thailand yang digunakan dan bentuk bahasa Pijin yang berkembang di tengah-tengah mahasiswa Thailand di Tanggerang. Secara rinci dapat dilihat pada tabel 1.

Tabel 1. Bahasa Pidjin Melayu Thailand ke Bahasa Indonesia

\begin{tabular}{lll}
\hline \multicolumn{1}{c}{ Melayu Thailand } & \multicolumn{1}{c}{ Indonesia } & Pidjin \\
\hline Magi & Kemari & Mari \\
\hline No'nok & Mau & Na'/no' \\
\hline Gi & Pergi/Ayo & Pegi/ Gih \\
\hline Lepah tuh & Setelah itu & Pah tuh \\
\hline Rile & Rileks & Rilek \\
\hline Siki & Sedikit & Sikit \\
\hline Hagho & Harga & Haga \\
\hline Tugah & Tugas & Tugah \\
\hline Pisentasi & Presentasi & Pesentasi \\
\hline Esok & Besok & Beso' \\
\hline Ta' hau & Tidak tahu & Ta' tau \\
\hline Masu' & Masuk & Maso' \\
\hline Gimano & Kemana & Gimano \\
\hline
\end{tabular}

Dari tabel 1. terlihat bahwa ada 13 (tiga belas) contoh bahasa Melayu Thailand yang digunakan oleh para mahasiswa Thailand yang berada di Tanggerang. Di antaranya Magi, No'nok, Gi, Lepah tuh, Rile, Siki, Hagho, Tugah, Pisentasi, Esok,Ta' hau,Masu', dan Gimano. Bahasa Melayu Thailand ini, tidak banyak mengalami perubahan dalam bentuk Pijinn-nya. Hanya terjadi perubahan sedikit pada struktur dan bunyi kata.

Pada tabel 2. merupakan contoh kalimat dari bahasa Melayu Thailand dan bentuk Pijin dari bahasa tersebut di Indonesia.

Tabel 2. Bahasa Pidjin Melayu Thailand ke Bahasa Indonesia

\begin{tabular}{ccc}
\hline Melayu Thailand & Indonesia & Pidjin \\
\hline Magi sining & Kemari ke sini & Mari ke sini \\
\hline Saya no'nok maing & Saya mau bermain & Saya na' main \\
\hline Makene gapo/ apo nih? & Ini makanan apa?, & Ni makan apa? \\
\hline Demo no' gimano? & Kamu mau kemana? & Kamu no' gimano? \\
\hline Tugahku hok mano? & Tugas aku yang mana? & Tugah aku yang mane' \\
\hline
\end{tabular}

Berdasarkan tabel 2, kata no'nok merupakan bahasa Melayu Thailand yang berarti mau. Setelah mengalami pijinisasi ke dalam bahasa Indonesia, berubah 
menjadi na'. Kata lepah tuh merupakan bahasa Melayu Thailand yang berarti setelah itu. Setelah mengalami pijinisasi ke dalam bahasa Indonesia, berupa menjadi pah tuh. Kata gimano merupakan bahasa Melayu Thailand yang berarti ke mana. Setelah mengalami pijinisasi ke dalam bahasa Indonesia, menjadi gimano.

Selanjutnya, kata magi dan sining dalam kalimat tersebut merupakan bahasa Melayu Thailand yang berarti kemari dan sini. Setelah mengalami pijinisasi ke dalam bahasa Indonesia, berubah menjadi mari dan sini. Kata no'nok dalam kalimat tersebut merupakan bahasa Melayu Thailand yang berarti mau. Setelah mengalami pijinisasi ke dalam bahasa Indonesia, berubah menjadi na'. Kata makene dan gapo/apo dalam kalimat tersebut merupakan bahasa Melayu Thailand yang berarti makanan dan apa. Setelah mengalami pijinisasi ke dalam bahasa Indonesia, berubah menjadi makan dan apa. Pada kata makanan juga terdapat penghilangan imbuhan an, menjadi makan. Kata demo, no' dan gimano dalam kalimat tersebut merupakan bahasa Melayu Thailand yang berarti kamu, mau dan ke mana. Setelah mengalami pijinisasi ke dalam bahasa Indonesia, berubah menjadi kamu, na' dan gimano. Kata tugah, hok dan mano dalam kalimat tersebut merupakan bahasa Melayu Thailand yang berarti tugas, yang dan mana. Setelah mengalami pijinisasi ke dalam bahasa Indonesia, berubah menjadi tugah, yang dan mane'.

\section{Pembahasan}

Wolff mencanangkan pandangan bahwa bahasa Austronesia harus dikaitkan dengan rumpun bahasa Indo-Cina (dalam Anceaux, 1994). Kemungkinan pengaruh bahasa dan bukannya hubungan kekerabatan, yang didesakkan ini antara lain dilakukan oleh R.A Kern. Pandangan yang berbeda diketengahkan oleh Paul Benedict, yang percaya bahwa boleh jadi bahasa Austronesia memiliki hubungan kekerabatan dengan dua kelompok bahasa berikut: dengan sekelompok bahasa yang dituturkan di wilayah perbatasan Vietnam Cina (bahasa Kandai), dan dengan rumpun bahasa Thai, yang menurut pendapatnya harus dipisahkan dari rumpunan bahasa Soino-Tibet, sebab 
kemiripan bahasa Thai dan bahasa Cina adalah karena pengaruh bahasa, bukan karena kesamaan asal bahasa.

Penggunaan bahasa Melayu ini juga dipakai oleh sebagian masyarakat Thailand Selatan. Dialek Melayu Patani merupakan bahasa yang dituturkan oleh masyarakat Melayu yang tinggal di Thailand Selatan terutama wilayah Pattani, Narathiwat, Yala dan Songkhla (Jahwae, 2014). Penutur bahasa Melayu terdapat di beberapa wilayah di negara Thailand seperti wilayah Pattani, Yala, Narathiwat, Songkhla (Thepha, Sabayoi, Nathewi, Chena, Sadau dan Ranood), Satun (Bandar Satun, Ban Kuan, Cekbilang, Tamalang, Koh Adang dan Koh Sarai), Nakhon Si Thammarat (Muang, Thasala, Hua Thaphan, Mokhlan dan Ron Phiboon), Krabi (Muang, Koh Ca, Koh Poo dan Koh Pipi, Koh Lanta, Koh Lanta Yai, Khau Phanom, Nakhau, Aulek di Ban Klang dan Ban Chong Mai Dam di Klang Hin), Phuket (Muang, Lam Tuk Kae, Koh Sire, Ban Sapha dan Had Ra Wai), Phatlung (Kong Ra, Chelem dan Jarad), Trang (Kan Tang di Kantang Tai dan mukim Koh Li Bung), Suratthani (Koh Marid dan Samui), dan Thai (Nong Chok ibu kota Bangkok, Samut Prakan, Nonthaburi dan Pathum Thani).

Bahasa Pijin dan Kreol adalah kajian linguistik yang muncul karena adanya hubungan bahasa dengan masyarakat sosial. Dalam jurnal tentang bahasa Pijin dan Kreol menerangkan bahwa Pijin adalah bahasa dengan penyederhanaan berbagai bentuk bahasa yang digunakan untuk kebutuhan dalam kontak komunikasi. Di lain pihak Kreol adalah Pijin yang telah berkembang dan memiliki penutur asli. Tok Pisin adalah bahasa Kreol yang telah mempunyai penutur asli dan telah memiliki, baik tata bahasa, bunyi kata maupun bahasa tersendiri. Bahasa Pijin memiliki ciri-ciri sebagai berikut;

a. tidak memiliki infleksi morfologi;

b. cenderung menggunakan konjungsi untuk mengacu ke makna kata "untuk";

c. tanda-tanda yang menunjukkan tense cenderung dihilangkan;

d. memiliki pronomina yang tidak bervariasi;

e. cenderung menghilangkan tanda-tanda persesuaian (agreement markers);

f. penggunaan makna leksikal sedikit; dan

g. preposisinya direduksi ke dalam bentuk tunggal atau bentuk umum. 
Bahasa Kreol berdasarkan perkembangannya (yang dipakai oleh sebuah generasi) dapat melalui tahap-tahap sebagai berikut:

a. merupakan kelanjutan pijin tanpa ada peubahan substansial;

b. Kreol dalam perkembanganya bisa punah (misalnya Gullah dan Negerhollands = bahasa yang pernah ada di Kepulauan Virginia);

c. Kreol akan mengalami evolusi hingga menjadi sebuah bahasa "normal";

d. Kreol secara berangsur-angsur menyatu dengan korespondensi dengan bahasa standar (misalnya yang terjadi di Jamaika);

Dalam prosesnya, Kreol dapat mengalami hal-hal sebagai berikut.

a. Dekreolisasi (Decreolization)

Proses peleburan sebuah Kreol ke dalam Pijin semula dan terjadi bila Kreol itu bertemu dengan Pijin semula.

b. Kontinm Pascakreol (Post-creol Continuum)

Proses dimana rangkaian variasi-variasi bahasa yang berkembang bila penutur Kreol diajari berbahasa standar.

c. Hiperkreolisasi (Hypercreolization)

Perkembangan sejenis Kreol yang merupakan reaksi yang sangat menjauh dari bahasa standar ( jurnal pijinisasi dan kreolisasi).

Perkembangan bahasa yang ada di dalam komunitas tertentu harus disikapi secara positif (Ardi, 2015). Begitu juga dengan perkembangan bahasa Melayu Thailand yang juga cukup berkembang pada saat ini dikarenakan banyaknya komunitas masyarakat yang menggunakan bahasa tersebut. Sebagaimana yang terjadi di Tanggerang, mahasiswa yang berasal dari Thailand menggunakan bahasa Melayu Thailand di dalam berkomunikasi sehari-hari.

Siegel (1997) menekankan bahwa meskipun perkembangan bahasa Pijin dan Kreol begitu pesat, namun kesuksesan di dalam komunikasi ditentukan juga oleh penguasaan penutur terhadap bahasa yang berlaku di daerah tersebut atau penguasaan terhadap bahasa nasional yang digunakan oleh kelompok masyarakat di sekitar tempat tinggalnya. Namun, jika bahasa Pijin dan Kreol memiliki kesamaan bentuk dan bunyi dengan bahasa yang digunakan di tengahtengah masyarakat tersebut, maka tidak mengapa para penutur menggunakan 
bahasa Pijin dan Kreol untuk berkomunikasi dengan masyarakat sekitar (Woodward, 1973).

Penutur yang menggunakan bahasa daerah atau bahasa nasional yang berlaku di tengah-tengah masyarakat tempat mereka tinggal akan membuka peluang bagi mereka untuk berkomunikasi secara terbuka dan maksimal. Begitupun dengan mahasiswa Thailand yang berada di Tanggerang, mereka akan lebih cepat bisa memahami dan mengakrabkan diri dengan budaya dan tatanan yang ada di dalam masyarakat tersebut, apabila mereka mampu menguasai bahasa daerah yang ada di Tanggerang atau menguasai bahasa Indonesia.

Hal ini bertujuan untuk menghindari kesalahpahaman antara penutur dengan lawan bicara. Faraclas (2002) mengatakan bahwa bahasa Pijin dan Kreol memiliki perbedaan struktur bahasa, bentuk, dan bunyi. Maka, bisa saja bahasa Pijin dan Kreol memiliki bentuk dan bunyi yang tidak biasa didengar oleh masyarakat setempat, sehingga akan menimbulkan interpretasi yang beragam. Untuk menghindari kesalahpahaman tersebut, maka penutur lebih baik menggunakan bahasa yang biasa digunakan oleh masyarakat sekitar tempat tinggal mereka.

\section{Simpulan}

Bahasa Pijin di lingkungan mahasiswa Thailand yang tinggal di daerah Tangerang melalui proses pijinisasi dan kreolisasi sebagai proses yang beroposisi satu dengan lainnya. Namun, keduanya memiliki keterkaitan satu dengan lainnya. Proses pijinisasi secara umum merupakan penyederhanan bentuk bahasa. Misalnya secara morfologis (strukrur kata) dan sintaksis (struktur gramatikal), toleransi terhadap variasi-variasi fonologis (pengucapan), reduksi sejumlah fungsi, dan peminjaman secara luas kata kata dari beberapa bahasa. Di sisi lain, kreolisasi adalah perluasan terhadap morfologis, sintaksis, regulasi fonologis, peningkatan jumlah fungsi bahasa yang digunakan, dan perkembangan rasional dan stabilnya peningkatan sistem perbendaharaan kata. 


\section{Daftar Pustaka}

Anceaux, J.C. (1994). Bahasa-Bunga Rampai. Jakarta: Pusat Pembinaan dan Pengembangan Bahasa.

Ardi, N. (2005). Sikap terhadap Bahasa Melayu dan Penggunaannya di Kalangan Pelajar Universiti di Selatan Thailand. (Doctoral Dissertation, Universiti Teknologi MARA).

Faraclas, N. (2002). Nigerian Pidgin. London: Routledge.

Jehwae, P. (2014). Dilema Bahasa Melayu sebagai Bahasa Pengantar Pembelajaran di Pondok Pesantren Patai Thailand Selatan. Jurnal Da'bid, XIX (2). Universitas Fatoni Thailand Selatan.

Moleong, L. J. (2010). Metode Penelitian Kualitatif. Bandung: PT Remaja Rosdakarya.

Mutoharoh, M., Sulaeman, A., \& Goziyah, G. (2018). Interferensi Morfologi dalam Karangan Narasi Mahasiswa Thailand Semester IV Pendidikan Bahasa dan Sastra Indonesia FKIP Universitas Muhammadiyah Tangerang. Silampari Bisa: Jurnal Penelitian Pendidikan Bahasa Indonesia, Daerah, dan Asing, 1(1), 95. doi:10.31540/silamparibisa.v1i1.10

Noermanzah, N. (2017). Struktur Kalimat Tunggal Bahasa Sindang di Kota Lubuklinggau dan Pengaruhnya dalam Pembelajaran Bahasa Indonesia. AKSIS: Jurnal Pendidikan Bahasa dan Sastra Indonesia, 1(1), 13. doi:10.21009/aksis.010101

Siegel, J. (1997). Using a Pidgin Language in Formal Education: Help or Hindrance? Applied linguistics, 18(1), 86-100.

Simanjuntak, B. A. (2010). Melayu Pesisir dan Batak Pegunungan. Jakarta: Yayasan Pustaka Obor Indonesia.

Sudaryono. (2018). Metodologi Penelitian. Depok: Rajawali Pers.

Syamsudin \& Vismania, S D. (2009). Metode Penelitian Pendidikan Bahasa. Bandung: Remaja Rosdakarya.

Woodward Jr, J. C. (1973). Some Characteristics of Pidgin Sign English. Sign Language Studies, 3(1), 39-46. 